\title{
ABSORPTION AND EMISSION SPECTRA OF TETRAMERIC GOLD(I) COMPLEXES
}

\author{
A. VOGLER and H. KUNKELY \\ Institut für Anorganische Chemie, Universität Regensburg, \\ Universitätsstrasse 31, D-8400 Regensburg, Federal Republic of Germany
}

Received 18 May 1988

The lowest-energy absorption and cmisson bands of the complexes [Au(dithioacetate) $]_{4}$ and [Au (piperidine) $\left.\mathrm{Cl}\right]_{4}$ are assigned to a metal-centered $5 \mathrm{~d}-6 \mathrm{~s}\left(\mathrm{~A}_{2 \mathrm{~g}} \leftrightarrow \mathrm{A}_{1 \mathrm{~g}}\right)$ transition which is modified by the metal-metal interaction in the square-planar $\mathrm{Au}(\mathrm{I})_{4}$ moiety.

\section{Introduction}

Coordination compounds with a $\mathrm{d}^{10}$-electron configuration at the metal, such as $\mathrm{Cu}(\mathrm{I}), \mathrm{Ag}(\mathrm{I})$, and $\mathrm{Au}(\mathrm{I})$, have a remarkable tendency to form clusters [1]. At first sight this seems rather surprising since with a filled $d$ shell, d-orbital interaction should not yield any metal-metal bonding. However, some bonding can result from the stabilization of d-orbital-based MOs by configuration interaction (CI) with appropriate empty MOs derived from the higher-cnergy s and p metal orbitals [1]. This type of $\mathrm{CI}$ is also important for the metal-metal interaction of certain square-planar $\mathrm{d}^{8}$ complexes as indicated by absorption and emission spectroscopy $[2,3]$. Recently, we applied this general idea of $d / s$ CI to the interpretation of the electronic spectra of the tetrameric clusters $[\mathrm{Cu}(\mathrm{I}) \mathrm{LI}]_{4}$ with $\mathrm{L}=$ pyridine and morpholine [4]. Copper and iodide atoms together form a cubane core. The present work deals with tetrameric $\mathrm{Au}(\mathrm{I})$ complexes. In this case the metal atoms occupy the corners of a square.

\section{Experimental}

The complexes $[\mathrm{Au}(\mathrm{dta})]_{4}[\mathrm{~S}] \quad(\mathrm{dta}=$ dithioacetate) and $[\mathrm{Au}(\mathrm{pip}) \mathrm{Cl}]_{4}[6]$ (pip=piperidine) were prepared according to published procedures. Absorption spectra were measured in solution at room temperature on a Uvikon 860 absorption spec- trometer. Emission spectra of the complexes in ethanol glasses at $77 \mathrm{~K}$ were obtained on a Hitachi 850 spectrofluorimeter equipped with a Hamamatsu 928 photomultiplier. The luminescence spectra were corrected for monochromator and photomultiplier efficiency.

\section{Results}

The absorption spectrum of $[\mathrm{Au}(\mathrm{dta})]_{4}$ in $\mathrm{CS}_{2}$ (fig. 1) displays a band at $\lambda_{\max }=407 \mathrm{~nm}(\epsilon=1650)$

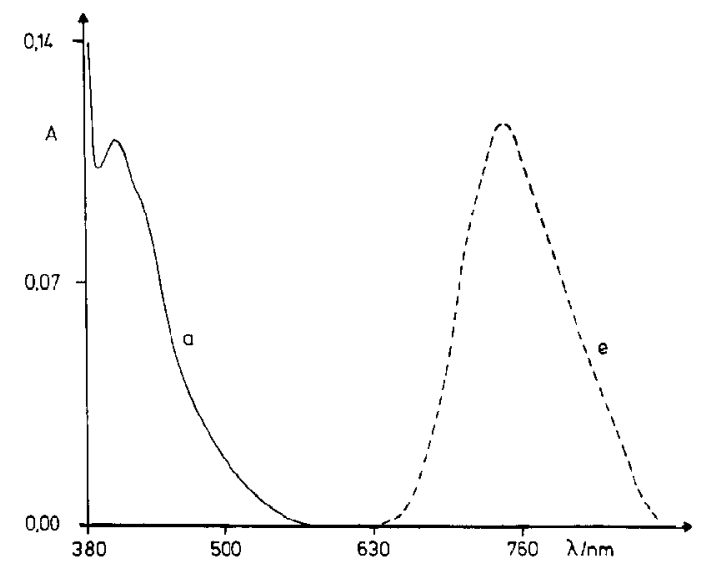

Fig. 1. Electronic absorption (a) and emission (e) spectra of [Au(dta) $]_{4}$. Absorption: $7.29 \times 10^{-5} \mathrm{M}$ in $\mathrm{CS}_{2}$ at room temperature, $1 \mathrm{~cm}$ cell. Emission: in $\mathrm{C}_{2} \mathrm{H}_{5} \mathrm{OH}$ at $77 \mathrm{~K} ; \lambda_{\text {exc }}=430 \mathrm{~nm}$, intensity in arbitrary units. 
which contains a long-wavelength shoulder at $430 \mathrm{~nm}$ $(\epsilon=1400)$. These values are close to those reported by Piovesana et al. [5]. The emission of [Au (dta) $]_{4}$ in ethanol glasses at $77 \mathrm{~K}$ was of medium intensity and appears at $\lambda_{\max }=743 \mathrm{~nm}$ (fig. 1). This luminescence was independent of the exciting wavelength $\left(\lambda_{\text {cxc }}>350 \mathrm{~nm}\right)$ but occurred only at low temperatures. The complex $[\mathrm{Au} \text { (pip) } \mathrm{Cl}]_{4}$ in ethanol shows its longest-wavelength absorption at $\lambda_{\max }=305$ $\mathrm{nm}(\epsilon=770)$. The emission of $[\mathrm{Au}(\mathrm{pip}) \mathrm{Cl}]_{4}$ in ethanol glasses at $77 \mathrm{~K}$ was somewhat weaker than that of the dta complex and appeared at $\lambda_{\max }=700$ $\mathrm{nm}\left(\lambda_{\text {exc }}=250 \mathrm{~nm}\right)$. Again, there was no luminescence in solutions at room temperature.

\section{Discussion}

The long-wavelength absorptions of $[\mathrm{Au}(\mathrm{dta})]_{4}$ were tentatively assigned to metal-to-ligand charge transfer (MLCT) transitions [5]. However, based on the similarity of the absorption and emission spectra of $[\mathrm{Au}(\mathrm{dta})]_{4}$ and $[\mathrm{Au}(\mathrm{pip}) \mathrm{Cl}]_{4}$ we suggest a different assignment since in the latter complex long-wavelength MLCT transitions cannot occur. Neither piperidine nor the chloride ligand provide empty low-energy orbitals.

Both complexes have the same basic structure (I). An important difference is the $\mathrm{Au}-\mathrm{Au}$ distance, which is smaller in the dta complex (3.013 $\AA$ ) [5] compared to $[\mathrm{Au}(\mathrm{pip}) \mathrm{Cl}]_{4}(3.301 \AA)$ [6].

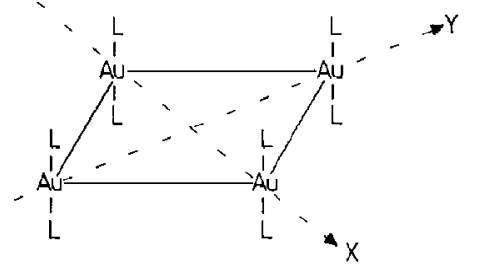

Since for $\mathrm{Au}(\mathrm{I})$ the $5 \mathrm{~d}-6 \mathrm{~s}$ energy separation is rather small and the $5 \mathrm{~d}-6 \mathrm{p}$ energy difference very large [7] only appropriate $5 \mathrm{~d}$ and the $6 \mathrm{~s}$ orbitals are considered for bonding interactions in the $\mathrm{Au}_{4}$ cluster. In the $\mathrm{Au}_{4}$ moiety ( $\mathrm{D}_{4 \mathrm{~h}}$ symmetry) each $\mathrm{Au}$ atom participates with one $d$ and one s orbital in $\sigma$ interaction with its closest neighbours. The bonding within and the optical lowest-energy transition of the cluster can be explained on the basis of a qualitative MO diagram which is derived from group theoretical

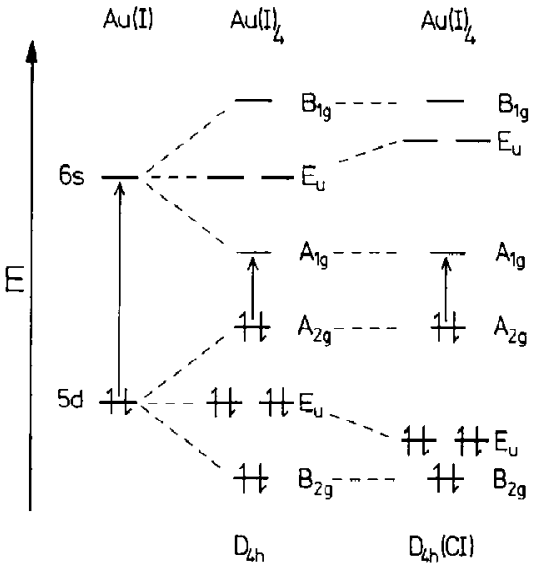

Fig. 2. Qualitative $\mathrm{MO}$ diagram of the $\mathrm{Au}(\mathrm{I})_{4}$ moiety including configuration interaction (CI).

considerations (fig. 2) [8]. The metal-metal bonding results only from $\mathrm{CI}$. The $\mathrm{d} / \mathrm{s}$ mixing leads to stabilization of the occupied degenerate $E_{u}$ orbitals, which are derived from the $5 \mathrm{~d}$ atomic orbitals.

For simple mononuclear Au(I) complexes of the type $\left[\mathrm{AuX}_{2}\right]^{-}\left(\mathrm{X}^{-}=\right.$halide $)$the longest-wavelength ds absorptions appear around $40000 \mathrm{~cm}^{-1}$ [9]. In the $\mathrm{Au}_{4}$ cluster the lowest-energy $5 \mathrm{~d} \rightarrow 6 \mathrm{~s}$ transition $\Lambda_{2 \mathrm{~g}}, \Lambda_{\mathrm{lg}}$ (fig. 2) is shifted to lower energies. Consequently, the longest-wavelength bands of $[\mathrm{Au}(\mathrm{dta})]_{4}$ at $\bar{\nu}_{\max }=23255 \mathrm{~cm}^{-1}$ and of [Au (pip) $\mathrm{Cl}]_{4}$ at $\bar{\nu}_{\max }=32786 \mathrm{~cm}^{-1}$ are assigned to the spin-allowed ${ }^{1} \mathrm{~A}_{2 \mathrm{~g}} \rightarrow{ }^{1} \mathrm{~A}_{\mathrm{lg}}$ transition. Since it is parity forbidden, these absorptions are only of moderate intensity. Compared to $[\mathrm{Au} \text { (pip) } \mathrm{Cl}]_{4}$ the $\mathrm{Au}-$ Au distance in $[\mathrm{Au}(\mathrm{dta})]_{4}$ is considerably smaller. This may be imposed by the bridging dta ligands [5]. The shorter distance increases the orbital overlap, which decreases the energy gap between HOMO and LUMO. Consequently, the ${ }^{\prime} A_{2 g} \rightarrow{ }^{1} A_{1 g}$ absorption undergoes a red-shift from $[\mathrm{Au}(\text { pip }) \mathrm{Cl}]_{4}$ to $[\mathrm{Au}(\mathrm{dta})]_{4}$.

The emission of both complexes is assigned to the spin-forbidden ${ }^{3} \mathrm{~A}_{1 \mathrm{~g}} \rightarrow{ }^{1} \mathrm{~A}_{2 \mathrm{~g}}$ transition. While the formal bond order within the $\mathrm{Au}_{4}$ clusters is zero in the ground state, it is one in the lowest excited state, since an electron is promoted from an antibonding $\left(A_{2 g}\right)$ to a bonding $\left(A_{1 g}\right)$ orbital. The large shift from absorption to emission is then at least partially due to the contraction of the $\mathrm{Au}_{4}$ square which should take 
place in the excited state. Compared to $[\mathrm{Au} \text { (pip) } \mathrm{Cl}]_{4}$ $\left(\Delta \bar{\nu}=18500 \mathrm{~cm}^{-1}\right)$ this shift is much smaller for $[\mathrm{Au}(\mathrm{dta})]_{4}\left(\Delta \bar{\nu}=9800 \mathrm{~cm}^{-1}\right)$. This observation may be explained by the fact that the $\mathrm{Au}-\mathrm{Au}$ distance in the dta complex is already rather short in the ground state. The excited-state contraction is now expected to be much smaller.

\section{Acknowledgement}

Support of this research by the Deutsche Forschungsgemeinschaft and the Fonds der Chemischen Industrie is gratefully acknowledged. We thank Professor G. Gliemann for his help in the group-theoretical analysis.

\section{References}

[1] P.K. Mehrotra and R. Hoffmann, Inorg. Chem. 17 (1978) 2187, and references therein;

Y. Jiang, S. Alvarez and R. Hoffmann, Inorg. Chem. 24 (1985) 749, and references therein.

[2] G. Gliemann and H. Yersin, Struct. Bonding 62 91985) 87.

[3] A.P. Zipp, Coord. Chem. Rev. 84 (1988) 47.

[4] A. Vogler and H. Kunkely, J. Am. Chem. Soc. 108 (1986) 7211.

[5] O. Piovesana and P.F. Zanazzi, Angew. Chem. 92 (1980) 579 [Angew. Chem. Intern. Ed. Engl. 19 (1980) 561]; B.C. Chiari, O. Piovesana, T. Tarantelli and P.F. Zanazzi, Inorg. Chem. 24 (1985) 366.

[6] J.J. Guy, P.G. Jones, M.J. Mays and G.M. Sheldrick, J. Chem. Soc. Dalton (1977) 8.

[7] L.E. Orgel, J. Chem. Soc. (1985) 4186.

[8] H.L. Schläfer and G. Gliemann, Basic principles of ligand field theory (Wiley, New York, 1969).

[9] M.E. Koutek and W.R. Mason, Inorg. Chem. 19 (1980) 648; M.M. Savas and W.R. Mason, Inorg. Chem. 26 (1987) 301. 